\title{
Capturing first records at the Nepal NSC accelerometric network
}

\author{
*M. Bhattarai', U. Gautam ${ }^{1}$, R. Pandey ${ }^{1}$, L. Bollinger ${ }^{2}$, B. Hernandez ${ }^{2}$, and V. Boutin ${ }^{2}$ \\ ${ }^{\prime}$ Department of Mines and Geology, Lainchaur, Kathmandu, Nepal \\ ${ }^{2}$ DASE, Bruyères le Châtel 91297 Arpajon, France \\ (*Email:mb2058@yahoo.com)
}

\begin{abstract}
The 21 high gain short period velocimetric stations monitored by DMG/NSC allow detecting and locating every earthquake with magnitude greater than $M_{L}=2.2$ within Nepal, insuring the trigger of the seismic alert for every event above $M_{L}=4.0$. However, their dynamic is not sufficient to determine also the peak ground acceleration, velocity and displacement at very short distances from the largest earthquakes, an information which is needed as critical input to seismic hazard assessment models.

In spite of extrapolating at short distances attenuation laws constrained by the weak motion database only, NSC decided to acquire a strong motion database. The project began with the installation of 3 accelerometric stations in 2009 (AC23 sensors and GSR24 digitizers) in Pokhara (PKR at sediment), Kakani (KKN at rock) and Kathmandu (DMG at sediment). During the first year of acquisition these instruments recorded some events at relatively short distances, complementing the velocimetric records.

After describing the sites and stations, we showed some of the first records, described some automatic tools developed to estimate rapidly some aggressiveness parameters from these data. We then discuss very preliminary results illustrated, among others, by the october $17^{\text {th }} 2010$ Xizang earthquake $\mathrm{M}_{\mathrm{L}}=5.7$, recorded at all 3 stations in the range $103-174 \mathrm{~km}$.

Planned installation of additional stations, both at rock and sediment, and acquisition of the accelerometric signal over long time windows will help to constrain a strong motion database as well as evaluate strong ground motion and its variability in Nepal.
\end{abstract}

Keywords: Accelerometric network, seismic aggressiveness parameters, PGA, PGV, attenuation relationship

Recieved: 14 November 2010

\section{INTRODUCTION}

Seismicity has been monitored in Nepal since 1978 from a network of short period stations operated by the National seismological Centre of the Department of Mines and Geology (NSC/DMG Nepal) in collaboration with Département Analyse et Surveillance de l'Environnement (DASE/France). Currently, this network is composed of 20 vertical short period velocimetric stations, only 3 -components long period and short period station and one broadb and station (Fig. 1). The seismic network allows detecting and locating every earthquake with magnitude greater than $M_{t}=2.2$ within Nepal (Pandey et al. 1999). Furthermore, it insures the trigger of the seismic alert for every seismic event above $M_{L}=4.0$. Most of the velocimetric data acquired can be derived into accelerations, and be used to constrain a seismic attenuation law for Nepal, a necessary input to Seismic Hazard models. However, the dynamic of the velocimetric stations operated is not sufficient to cover the whole range of velocities from very small to large earthquakes, respectively at long and short distances. Therefore, most of the stations at short distances from revision accepted: 13 April 2011

the largest earthquakes saturate. A proper ground velocity measure or ground acceleration derivation cannot be performed. As a result, the Nepal attenuation law lacks some strong motion records at short distances, a necessary input for seismic hazard assessment studies.

Some solutions may help to overcome that limitation. One of them is the use of attenuation laws calibrated from strong motion data acquired in similar contexts (Singh et al. 1996; Sharma 1998; Pandey et al. 2002; Nath et al. 2008). However, the scarcity of strong motion available in the Himalaya as well as the large variability within these data account for the installation of some additional stations in Nepal.

The purpose of this article is to describe the characteristics and setting of three new strong motion instruments installed in Kathmandu, Kakani and Pokhara. We then described some specific software that have been developed to allow NSC to quickly analyse the accelerograms and translated them into seismic aggressiveness parameters. We finally described some preliminary results coming from the interpretation of the very first records. 


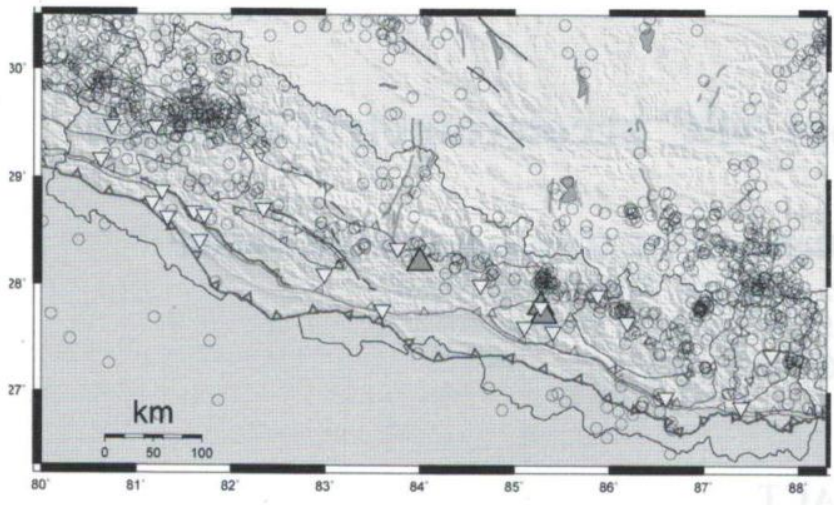

Fig. 1: Seismicity recorded between 1995 and 2010 by National Seismological Centre, Department of Mines and Geology. Events with magnitude greater than $M L=4$ are shown. These earthquakes correspond to events triggering the seismic alert. The small down triangles correspond to the 21 short period stations of the Seismic network, the larger up triangles correspond to the accelerometric stations.

\section{INSTRUMENT TO PROCESSING}

\section{Instrumentation}

Three strong-motion instruments have been installed in Kathmandu (DMG), Kakani (KKN) and Pokhara (PKR) in 2009. All stations are composed of a 3 components accelerometric sensor (GeoSIG AC23) connected to a 24bit digitizer (GeoSIG GSR-24), sampling at $200 \mathrm{~Hz}$. The dynamic range of the instruments is larger than $125 \mathrm{~dB}$ within the $0.1-35 \mathrm{~Hz}$ band. The full scale is set at $\pm 1 \mathrm{~g}$. The stations are not currently telemetered. Only the signals with significant acceleration peak compared to the background noise or an acceleration peak over a fixed threshold are stored on a local memory card.

Because the variations of the noise level at DMG and PKR are highly variable due to a very high level of anthropic noises, a STA/LTA (short time average/ long time average) trigger mode has been chosen and set at $20 \mathrm{db}$. The advantage of this trigger mode from an absolute threshold trigger method is that it allows recording events with relatively low acceleration peaks while avoiding overloading the memory card due to a punctual increase of background noise. The background noise level being lower at KKN, an absolute threshold is set at $0.001 \mathrm{~g}(0.1 \%$ of the full scale). This threshold is theoretically sufficient for the accelerometers to be triggered by $M_{L}=5, M_{L}=4$ and $M_{L}=3$ events, respectively within about $100 \mathrm{~km}, 30 \mathrm{~km}$ and $10 \mathrm{~km}$ according to an attenuation relationship calibrated in France using a similar $M_{L}$ as the one calculated by NSC (Marin et al. 2004), and therefore, coherent with the NSC parameter determination, or $\mathrm{Mw}=4, \mathrm{Mw}=3, \mathrm{Mw}=2$ events, respectively within about $100 \mathrm{~km}, 55 \mathrm{~km}$ and $30 \mathrm{~km}$ according to one of the most recent Garwhal ground motion prediction equation expressed as a function of the $M_{w}$ (Nath et al. 2005, 2008).

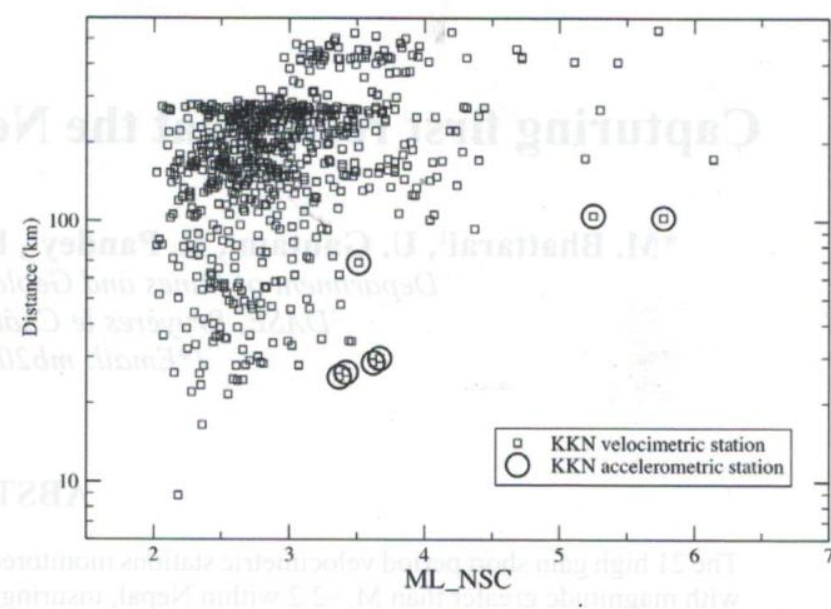

Fig. 2: Earthquakes recorded by Kakani seismic station between $01 / 01$ and 18/10/2010 as a function of their magnitude and distance to the station (squares). The circles characterise events that triggered the accelerometric station.

Background noise is not the only difference between the stations, since one of the stations is installed at hard rock $(\mathrm{KKN})$, a weathered granite, while DMG and PKR stations are installed in Kathmandu and Pokhara sedimentary basins. The pre and post events recording time windows set for all instruments at 5 and $10 \mathrm{~s}$ up to September 2010 were not sufficient and have been changed to 10 and $40 \mathrm{~s}$.

\section{DATA PROCESSING AND AGGRESSIVENESS ESTIMATOR DETERMINATION}

Once the accelerograms are collected following an earthquake, the DIAMANT software (Hernandez et al. 2011 ) is used to rapidly assess the aggressiveness of the seismic motion. The last version of this software computes several parameters of aggressiveness and produces classical graphical representation used for risk applications. The aggressiveness parameters computed are the most commonly used in the engineering domain, at present, and refer to physical consideration such as peak parameters, duration estimates, spectral amplitudes or energetic values. These parameters are described hereafter but the outputs of the software are illustrated in next section.

The peak parameters computed are the peak ground acceleration (PGA), the peak ground velocity (PGV) and the peak ground displacement (PGD). The PGA is a basic measure of earthquake aggressiveness but used alone is not totally reliable for damage estimation. The examination of recorded seismic events shows that a lot of seismic motion with a large PGA can not produce appreciable structural damage, while some earthquakes generating rather small PGA can produce a high level of destruction (Housner et al. 1982; Betbeder-Matibet 2003). The PGV seems to be a more representative measure of seismic motion strength as 
it is linked with the energy (Housner et al. 1982; BetbederMatibet 2003)

All the parameters calculated from time series integral depend upon the duration of the earthquake. Close to the seismic source the vibration duration is a parameter that cannot be predicted with any confidence for a given magnitude, distance and soil type. In addition, observations from different earthquakes show that the duration of ground motion largely influences the level of structural damage. Records with large acceleration and spectral values can produce slight damage if the duration is short whereas records with moderate acceleration and long duration can be very destructive. Defining strong ground motion duration in relation to the main energy content is a difficult issue. In regard to this (Trifunac and Brady 1975) have defined the Trifunac duration, as the time elapsed between 5\% and $95 \%$ of the Husid diagram, which is the time history of the seismic energy scaled to the total energy.

Energetic parameters determined from time integral are intrinsically much more relevant to quantify the aggressiveness of a seismic signal than peak values or strong ground motion durations. DIAMANT determines two strong ground motion aggressiveness parameters based on such time series integrations. The Arias intensity is the time-integral of the square of the ground acceleration normalized by pi divided by two times the gravity value at the observation site. DIAMANT determines the Cumulative Absolute Velocity (CAV) defined as the integral of the absolute acceleration time series is also calculated. The CAV and the Arias intensity are useful to estimate the possible onset of structural damage and liquefaction of saturated soils (Kayen and Mitchell 1997).

Most of damage estimations of seismic signal are based on parameters relating to the response of a linear elastic single-degree-of-freedom system. Acceleration, velocity and displacement response spectra represent the response of elastic single-degree-of-freedom systems. The fundamental frequency and the damping factor are the only parameters needed to characterize dynamically the system. Spectral shape and amplitudes can be assumed to be basic measures of seismic potential. The maximum pseudo-acceleration is a measure of the maximum strength demand of the earthquake. It is proportional to the maximum seismic force acting on the structure. The maximum pseudo-velocity is a measure of the kinetic energy of the seismic motion. The maximum displacement of the response spectrum is a measure of the maximum displacement demand. It controls structural damage of multi-storey buildings due to lateral displacement.

The DIAMANT software displays the response spectrum at the ADRS (Acceleration Displacement Response Spectra) format. The application of the Capacity-Spectrum technique requires that both the demand response spectra and the structural capacity (or pushover curves) be plotted in the spectral acceleration versus spectral displacement domain. A spectrum plotted this way is known as ADRS representations.
Finally, the Housner spectrum intensity (Housner 1952) is also computed. It is the integral of the pseudo-velocity spectrum in the range $0,4-10 \mathrm{~Hz}$ (frequency interval of interest in earthquake engineering). It can be interpreted as an integral measure of the energy demand.

\section{RESULTS AND DISCUSSIONS}

During the first months of acquisition, more than 4000 accelerometric events were detected. Although most of them correspond to local cultural noise events, some have been triggered by earthquakes.

Kakani strong motion instrument $(\mathrm{KKN})$ recorded 7 events with $M_{L}$ within the range 3.4 to 5.8 at epicentral distances between 25 and $105 \mathrm{~km}$ (Fig. 2). This station is colocated with a short period vertical component velocimetric station (ZM500) with a low and high gain channel, insuring a very large dynamic at this site. The absolute threshold set at $0.001 \mathrm{~g}$ for the strong motion instrument guarantees a significant overlap between the accelerometric and low gain velocimetric components at the site (Fig. 2).

As a first example of signal recorded at Kakani, we focussed on an event from July the $15^{\text {th }} 2010$ at $20 \mathrm{~h} 15$, a magnitude $\mathrm{M}_{\mathrm{L}} 3.4$ recorded at very short epicentral distance $(25 \mathrm{~km})$ according to the location performed by NSC using the seismic network. Note that the time delay between the P and $S$ wave first arrivals, $\sim 4 \mathrm{~s}$, obvious on the accelerogram (Fig. 3), is in accordance with this distance estimate, taking into account reasonable uncertainties on the estimate of the shallow depth of the earthquake as well as on the $V_{s}$ and $V_{p}$ waves velocities.

The mean horizontal PGA for this event is $0.853 \mathrm{~cm} \cdot \mathrm{s}^{-2}$, larger than the 0.3 to $0.4 \mathrm{~cm} \cdot \mathrm{s}^{-2}$ predicted by the French attenuation law (Marin et al. 2004) but smaller than the 3.6 to $4.6 \mathrm{~cm} . \mathrm{s}^{-2}, 9.7$ to $11.4 \mathrm{~cm} . \mathrm{s}^{-2}$ and 16.7 to $18.8 \mathrm{~cm} . \mathrm{s}^{-2}$ estimated using respectively ground motion prediction equation calibrated in other regions of the Himalayas (Nath et al. 2007, Nath et al. 2005 and Singh et al. 1996). Note that these values have been estimated assuming that these laws can be extrapolated to such small magnitude events, taking also into account the very strong assumption that $\mathrm{M}_{\mathrm{w}}=\mathrm{m}_{\mathrm{b}}=\mathrm{M}_{\mathrm{L}}$ as well as neglecting the typical discrepancy of the measures induced by source, path and site effects.

The theoretical PGV calculated using Singh et al. (1996) Himalayan attenuation law also overestimates significantly the recorded value, with a mean horizontal PGV measured at $0.021 \mathrm{~cm} \cdot \mathrm{s}^{-1}$, versus a predicted one at 24 to $28 \mathrm{~cm} \cdot \mathrm{s}^{-1}$, suggesting that either the assumptions taken into account here are not valid, or that the Nepalese ground motion prediction equation differs significantly from the one calibrated in other regions of the Himalayas, or both.

Figs. 3 and 4 illustrate also the output of the other aggressiveness parameters introduced in section 1. Note 


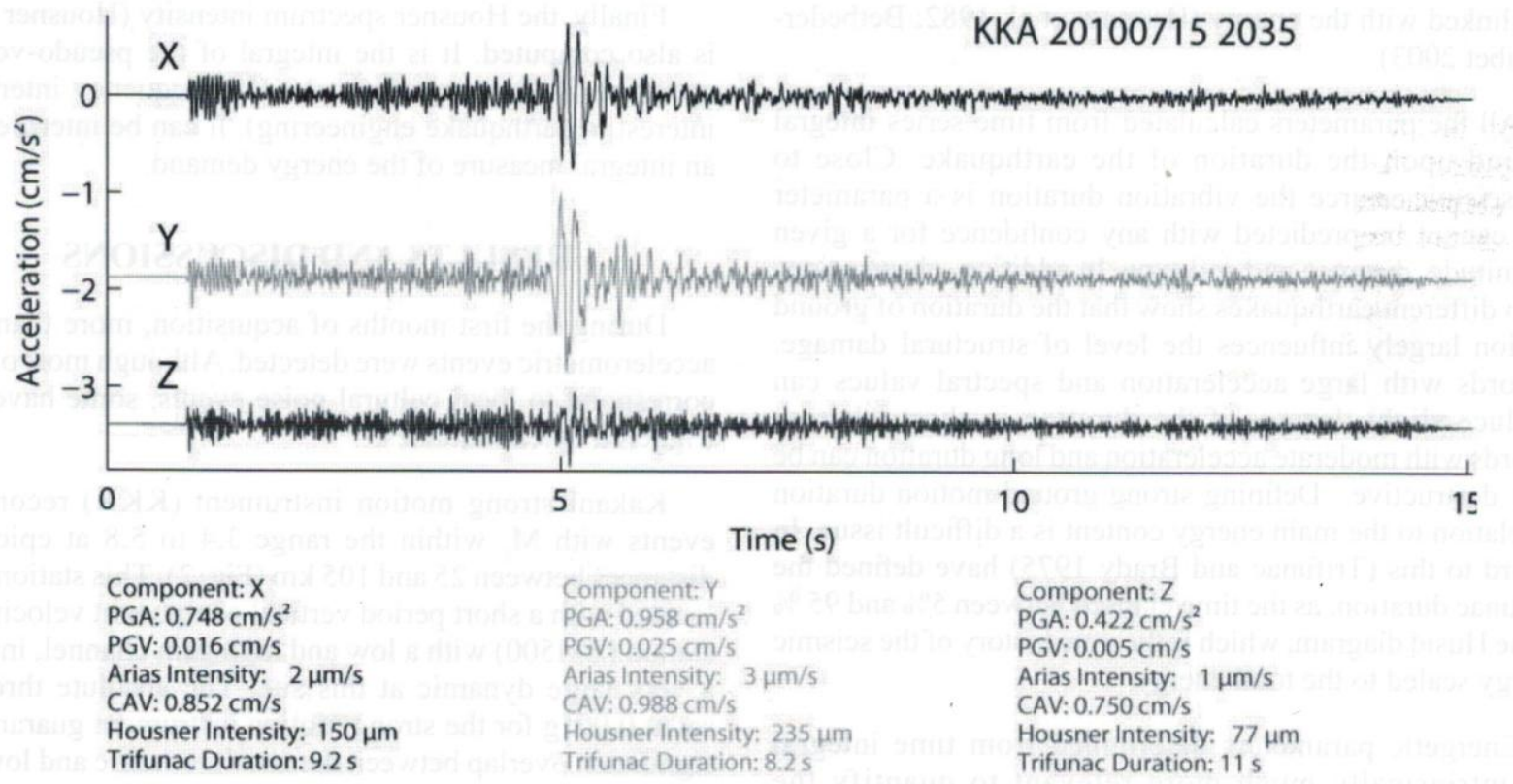

Fig. 3: An example of accelerometric signal recorded at KKN (Kakani) station on the 15/07/2010 at 20h35, an earthquake of $M_{L}=3.4$ recorded at $25 \mathrm{~km}$.

that most of the parameters calculated here in Fig. 4 for a moderate event, are out of the range within which they have been calibrated or are usually used, the July the $15^{\text {th }} 2010$ earthquake recorded at Kakani being very small. In particular some parameters or representations such as the PGD or the seismogram in displacement are not reliable enough when the signal is too weak. Furthermore, this event recorded at only one station may not be representative at all, with its particular source, or path or site effect.

Further examination of the whole dataset, including larger events recorded at more than one station is needed. Although the number of events recorded is still very small, some intriguing results appear. Overall horizontal/vertical component ratios at the strong motion instruments are systematically lower for the two stations within basins (DMG and PKR) than at KKN on hard rocks (Fig. 5).

This characteristic might be due to sedimentary site effects at DMG and PKR. It may also be induced by a topographical effect at $\mathrm{KKN}$ station, the instrument being installed on the top side of a ridge, at a place where waves refracted by the topography might constructively interfere with direct arrival (Bouchon 1973). It may also be only coincidental given the very small number of events recorded at basin station.

To go further into the understanding of that result, we looked for events recorded at several stations. The 3 strongmotion instruments were triggered by an event on October 17th 2010. This earthquake of $M_{L}=5.7$, felt at Kathmandu, occurred at $20 \mathrm{~h} 11 \mathrm{mn}$. Recorded at all NSC velocimetric stations, it has been located on the Southeastern end of the
Gyirong graben active fault system at epicentral distances to PKR, DMG, KKN of 174, 110 and 103 km respectively. The depth of the event appears uncertain. It is poorly constrained by the sole NSC stations given the location of the event outside the seismic network, roughly constrained by depth phase (pP) that have been picked about 17 to $21 \mathrm{~s}$ after the $\mathrm{P}$ at teleseismic distances, suggesting a depth of about $\sim 80 \mathrm{~km}$

The inspection of the signal at DMG shows that there are almost no $\mathrm{S}$ waves but strong $\mathrm{P}$ on the vertical component, which is not the case at all at $\mathrm{KKN}$, a few kilometers northward (Fig. 6). This could be due to a basin effect: hard rocks, gneisses and granites, with high seismic wave velocities and high density, underlain Kathmandu basin and KKN station. The Kathmandu basin is filled with lower density rocks characterized also by lower seismic waves velocities. This juxtaposition of the two geological medium generates a strong impedance decrease. The incidence of the seismic ray is therefore, steeper than elsewhere as illustrated on Fig. 7. Further analysis of the site over reference spectral ratio put in evidence higher amplitudes at low frequencies for DMG (Fig. 8). These characteristics suggest a basin effect, the energy present at high frequencies at the rock site could be redistributed, and present at low frequencies within the basin It seems that the characteristic resonance of the Kahtmandu basin at DMG is of the order of $1-2 \mathrm{~Hz}$, this is consistant with the depth and composition of the basin at this site.

For the moment, none of the interpretations proposed can be ascertained on the sole basis of the few data available. Several complementary records, including signals coming from various source-stations azimuth, distances, depths and focal mechanisms will be needed to properly characterize some particular site effects and differentiate them from path or topographical effects. 


\section{KKA 201007152035}

- component: X
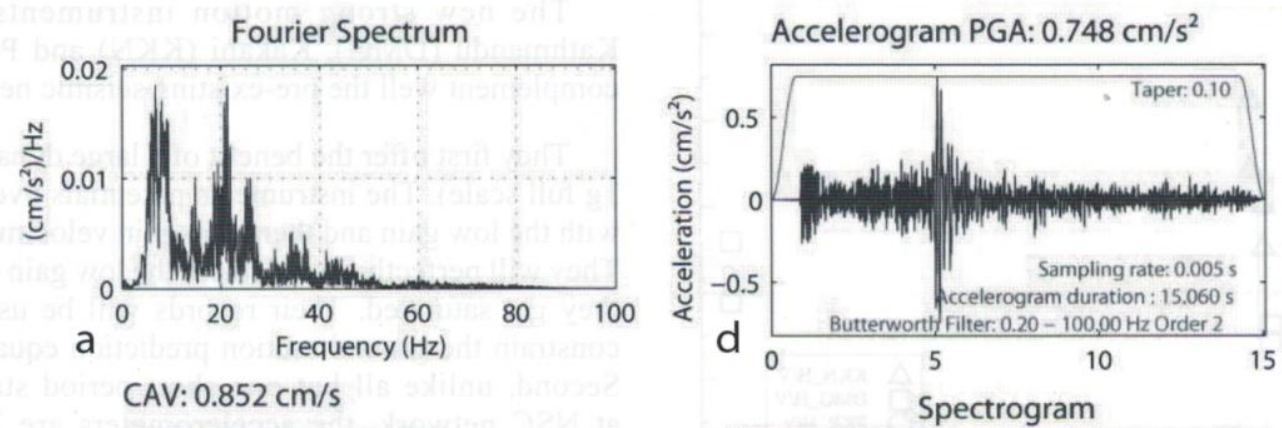

CAV: $0.852 \mathrm{~cm} / \mathrm{s}$

Arias Intensity: $2 \mu \mathrm{m} / \mathrm{s}$

Housner Intensity: $150 \mu \mathrm{m}$
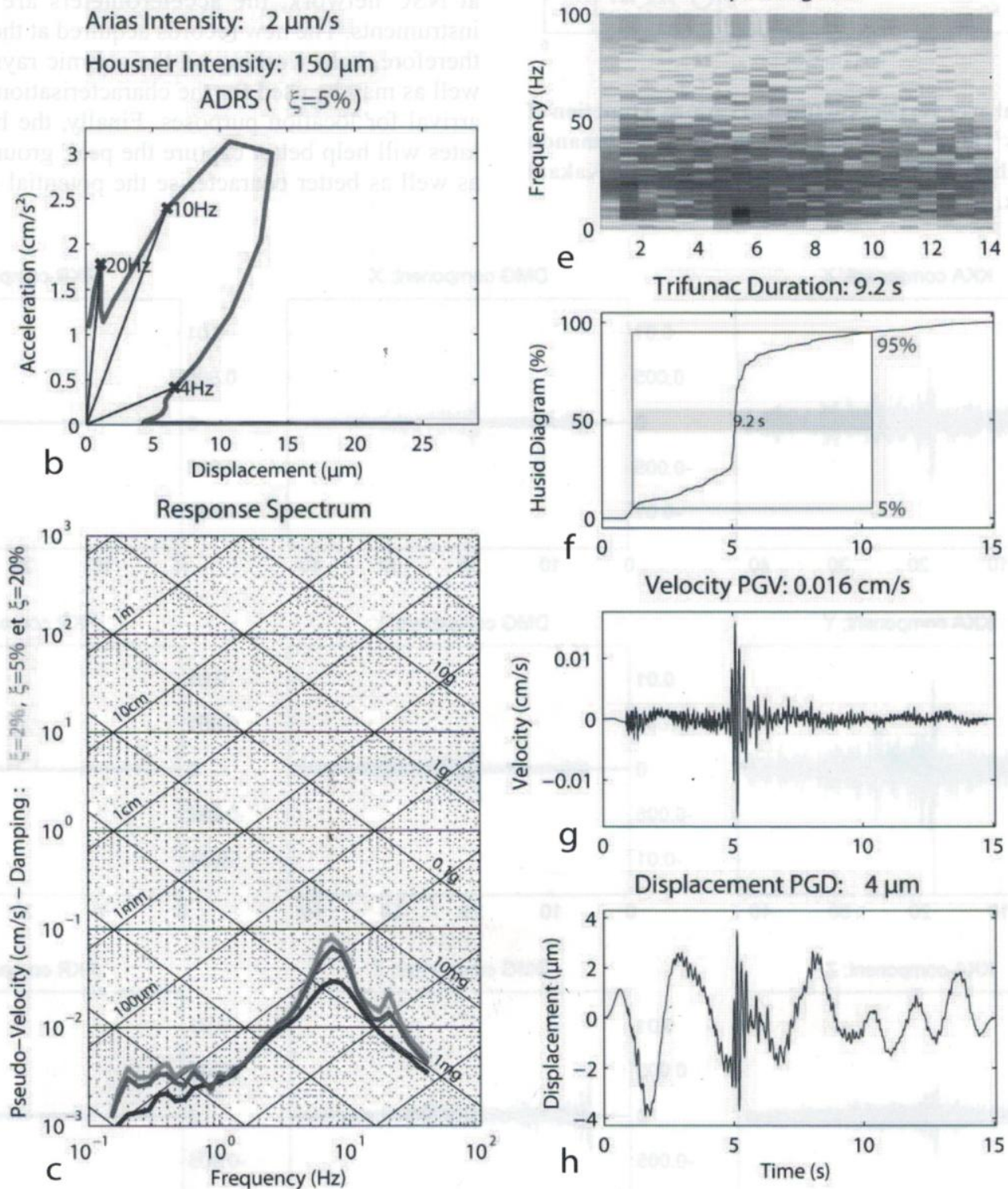

Fig. 4: An example of accelerometric signal analysis routinely executed using Diamant software (Hernandez et al. 2011) with the accelerometric signal. Here, the seismic motion is induced by an earthquake of $M_{L}=3.4$ recorded at $25 \mathrm{~km}$ and recorded at KKN (Kakani) station on the 15/07/2010 at 20h35. (a) Amplitude of the Fourier spectrum (b) Acceleration Displacement Response Spectra representation (c) Response spectrum on a trilogy diagram for 3 damping values (d) Accelerogram (e) Spectrogram between 0 and half the sampling frequency (f) Husid diagram (g) Velocigram (h) Sismogram in displacement. Refer to the text for further details. 


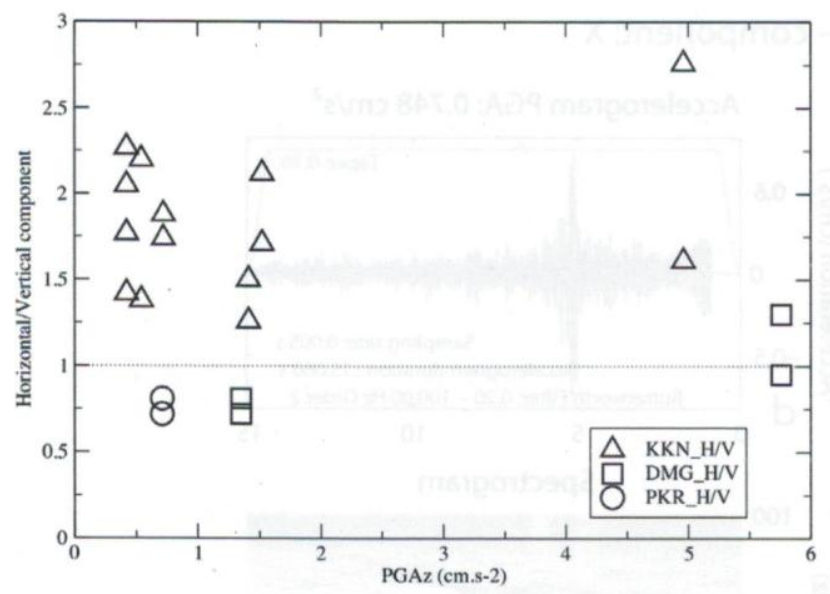

Fig. 5: Horizontal over vertical component ratio as a function of the PGA (in $\mathrm{cm}^{-\mathrm{s}^{-2}}$ ) for all 3 stations. Note that both Kathmandu (KTM) and Pokhara (PKR) are sediment sites, while Kakani $(\mathrm{KKN})$ is at rock.

\section{CONCLUSIONS}

The new strong motion instruments installed at Kathmandu (DMG), Kakani (KKN) and Pokhara (PKR) complement well the pre-existing seismic network.

They first offer the benefit of a large dynamic range (+/$1 \mathrm{~g}$ full scale). The instruments potentials overlap very well with the low gain and then high gain velocimetric channels. They will perfectly complement the low gain channels when they get saturated. Their records will be used in order to constrain the ground motion prediction equation in Nepal. Second, unlike all but one short period station installed at NSC network, the accelerometers are 3 components instruments. The new records acquired at these stations will therefore, help working on the seismic rays incidences, as well as may be used for the characterisation of azimuth ray arrival for location purposes. Finally, the higher sampling rates will help better capture the peak ground acceleration, as well as better characterise the potential response of the
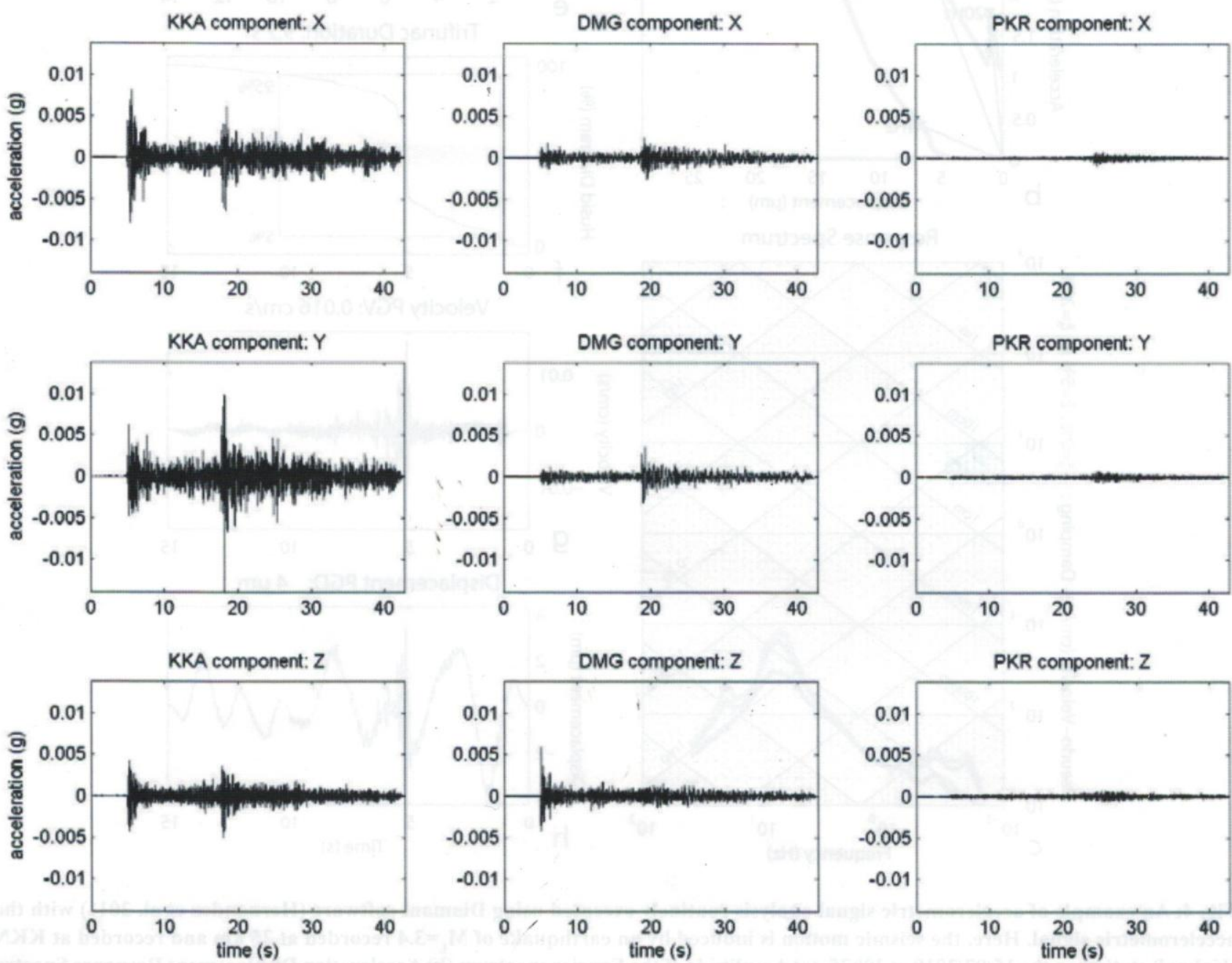

Fig. 6: Accelerograms, north, south and vertical components, of the 17/10/2010 $\mathrm{M}_{\mathrm{L}}=5.8 \mathrm{Xizang}$ earthquake recorded by KKA, DMG and PKR stations at respectively 103,110 and $174 \mathrm{~km}$. 


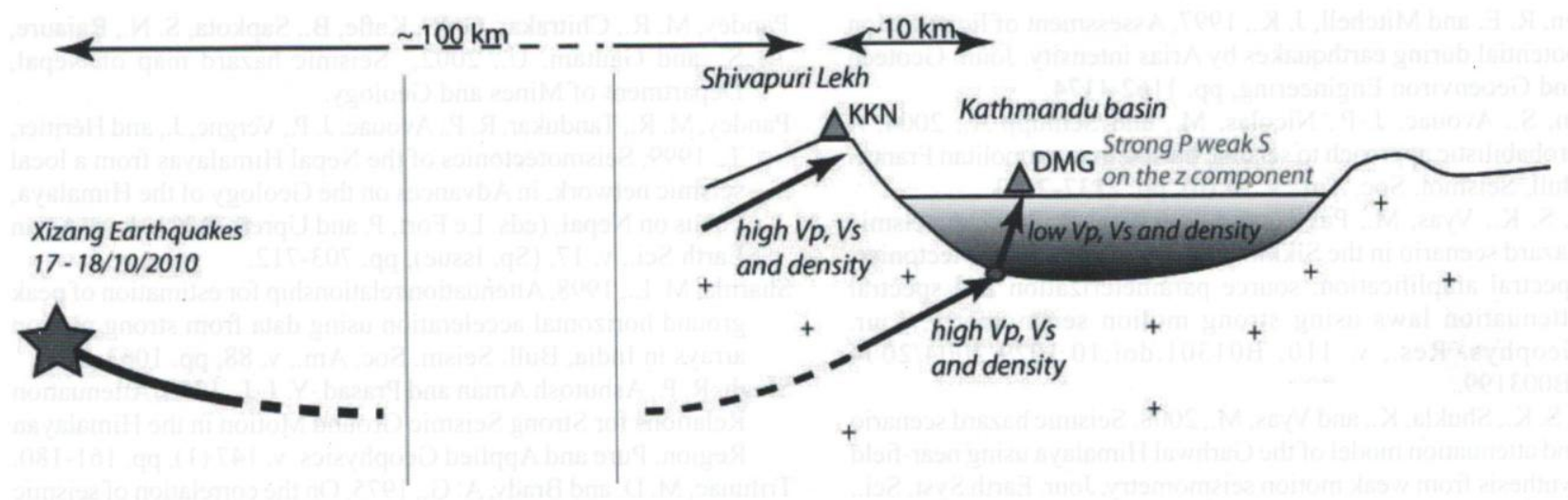

Fig. 7: Schematic representation of a possible basin effect
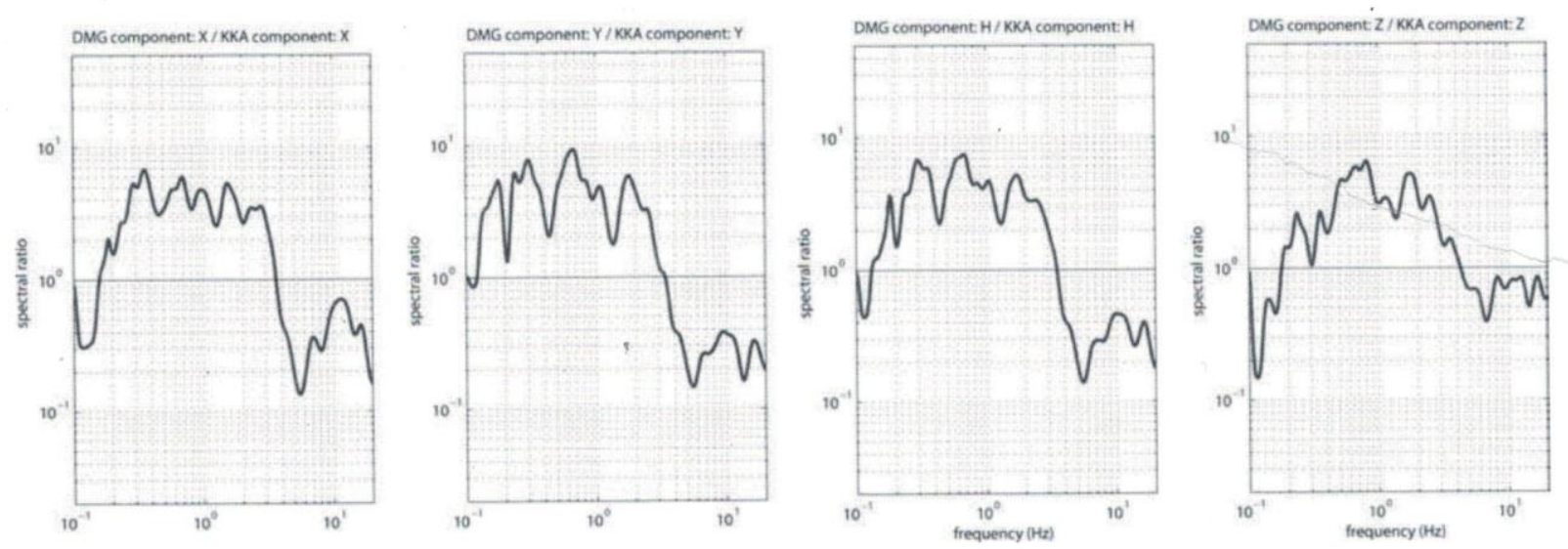

Fig. 8: Site over reference spectral ratios, here DMG over KKN, for the 17/10/2010 $\mathrm{M}_{\mathrm{L}}=5.8$ Xizang earthquake

buildings and equipments, sensitive to high frequencies seismic waves.

The purpose of this article is mainly to present the instrument characteristics, as well as present the automatic signal analysis toolboxes that have been developed specifically to meet the demand of quick signal analysis and seismic aggressiveness characterisation.

A strong motion database collection, needed to complement the weak motion data already available, will be collected with the 3 stations described. However, because the capture of a large database within a reasonably short period appears crucial, the existing strong motion instruments will be soon complemented with 3 additional stations. An action is already planned for early 2011. These additional stations, both at rock and sediment, and the acquisition of the accelerometric signal over long time periods, will help constrain a strong motion database as well as evaluate strong ground motion and its variability in Nepal.

\section{ACKNOWLEDGEMENTS}

The authors are most grateful to Mr. Sarbajit Prasad Mahato, Director of DMG and Soma Nath Sapkota, Chief of the National Seismological Centre (NSC) as well as to all the staffs of the NSC and DASE who have contributed to this project. Ronan Michard and Benoit Doury are particularly thanked for their assistance, as well as Sudhir Rajaure for his exchanges at the beginning of the project. We also thank two anonymous reviewers for their constructive comments.

\section{REFERENCES}

Betbeder-Matibet, J., 2003, Essai sur l'état de l'art et le sens des ordres de grandeur en génie parasismique. Hermès Sciences Publications Ed., v. 1-3 (In French).

Bouchon, M., 1973, Effect of topography on surface motion. Bull. Seismol. Soc. Am., v. 63, pp. 615-632.

Chandrasekaran, A. R. and Das, J. D., 1992, Strong motion arrays in India and analysis of data from Shillong array, v. 62, pp. 233-250.

Hernandez, B., L. Bollinger and V. Boutin, 2011, DIAMANT. Traitement des donneìes acceileìromeitriques et calcul d'indicateur de nocivité sismique. Guide d'utilisation. CEA/ DIF/DASE/LDG/2011/DO, pp. 1-34.

Housner, G. W., 1952, Intensity of ground motion during strong earthquakes. Technical Report: CaltechEERL:1952. EERL.1952.001.

Housner, G. W. and Jennings, P. C., 1982, Earthquake design criteria. EERI Monograph Series. Berkeley, CA: Earthquake Engineering Research Institute. 
Kayen, R. E. and Mitchell, J. K., 1997, Assessment of liquefaction potential during earthquakes by Arias intensity. Jour. Geotech and Geoenviron Engineering, pp. 1162-1174.

Marin, S., Avouac, J.-P., Nicolas, M., and Schlupp A., 2004, A probabilistic approach to seismic hazard in metropolitan France. Bull. Seismol. Soc. Am., v. 94 (6), pp. 2137-2163.

Nath, S. K., Vyas, M., Pal, I., and Sengupta, P., 2005, A seismic hazard scenario in the Sikkim Himalaya from seismotectonics, spectral amplification, source parameterization and spectral attenuation laws using strong motion seismometry, Jour. Geophys. Res., v. 110, B01301,doi;10.1029/2004/2004 JB003199.

Nath, S. K., Shukla, K., and Vyas, M., 2008, Seismic hazard scenario and attenuation model of the Garhwal Himalaya using near-field synthesis from weak motion seismometry, Jour. Earth Syst. Sci., v. 117, S2, pp. 649-670.
Pandey, M. R., Chitrakar, G. R., Kafle, B., Sapkota, S. N., Rajaure, S., and Gautam, U., 2002, Seismic hazard map of Nepal, Department of Mines and Geology.

Pandey, M. R., Tandukar, R. P., Avouac, J. P., Vergne, J., and Héritier, T., 1999, Seismotectonics of the Nepal Himalayas from a local seismic network, in Advances on the Geology of the Himalaya, Focus on Nepal, (eds. Le Fort, P. and Upreti, B.N.), Jour. Asian Earth Sci., v. 17, (Sp. Issue), pp. 703-712.

Sharma, M. L., 1998, Attenuation relationship for estimation of peak ground horizontal acceleration using data from strong motion arrays in India, Bull. Seism. Soc. Am., v. 88, pp. 1063-1069.

Singh, R. P., Ashutosh Aman and Prasad, Y. J. J., 1996, Attenuation Relations for Strong Seismic Ground Motion in the Himalayan Region. Pure and Applied Geophysics, v. 147 (1), pp. 161-180.

Trifunac, M. D. and Brady, A. G., 1975, On the correlation of seismic intensity scales with the peaks of recorded ground motion. Bull. Seismo. Soc. Am., v. 65, pp. 139-162. 